\title{
Queer linguistics and identity
}

The past decade

Lucy Jones

University of Nottingham, Nottingham, UK

\begin{abstract}
In this short essay, I offer some reflections on language and sexuality work over the past decade. My discussion is focused on the increasing influence of queer theory, in particular, and I comment on trends in research into language and queer identities. I take into account not only the work published in the Journal of Language and Sexuality and beyond, but also that presented over the past decade at the annual Lavender Languages and Linguistics conference.
\end{abstract}

Keywords: lavender linguistics, queer theory, normativity studies, nonbinary sociophonetics, language, sexuality and religion

\section{Introduction}

Since the publication of the first influential volumes taking a linguistic approach to the study of sexuality and queer identities (e.g. Leap 1995, Livia and Hall 1997), we have seen a huge increase in work in this area. Research into language and sexuality has gradually emerged as of central importance within sociolinguistics more broadly, and it no longer holds the minority status it perhaps once did. The creation of the Journal of Language and Sexuality (hereafter $J L S$ ) in 2010 has recently had a key part to play in this; it has amplified the voices of those engaged in this work and validated linguistic research into and about queer subjects. 
In conjunction with this, the international conference most closely aligned with language and sexuality (though not formally linked to $J L S$ ) - Lavender Languages and Linguistics, established in 1993 by William Leap - has seen great change in recent years. The annual conference has not only brought together those working in this area over the years, it has empowered new generations of researchers who consider themselves queer linguists first and foremost. I therefore frame the following reflections on language and sexuality work over the past decade in terms of not only the trends shown in $J L S$ and beyond, but also in terms of what we have seen happening at Lavender. In combination, this offers insights into developments in the field more broadly.

Firstly, it is useful to provide some brief context regarding the conference. Up to and including its twenty-third event in 2016, Lavender was hosted annually at American University, Washington D.C. Though already regularly including speakers from around the world, the conference began to move location each year and an increase in the number of international presenters followed. In 2017, Lavender was hosted at the University of Nottingham, England, and for the first time three parallel sessions were needed to accommodate the wide range of papers being presented. This increased to four parallel sessions two years later at the University of Gothenburg, Sweden. This increase certainly reflects the recent growth of research into language and sexuality.

Importantly, much of what has been presented at Lavender and published in JLS is not actually about sexuality: not all papers have sex and desire, sexual identity, or sexual orientation as their focus, with research focused on trans and genderqueer speakers increasing, for example. This is one reason why 'Lavender', a word associated with the gay community for much of the twentieth century and used in foundational work in the field (e.g. Leap 1995), continues to be associated with the conference; it symbolises the truly diverse nature of research that this community has produced. Although the name of $J L S$ suggests a 
narrower focus, what we have seen published here over the past 10 volumes certainly mirrors the increasingly diverse range of topics presented at the conference. I return to this particular point below, alongside reflections on the current and future status of the field. I then go on to consider what we have learnt about identity, in particular, through work taking an explicitly queer approach.

\section{The shifting focus of Lavender}

Baker's (2013) paper in $J L S$ argued that the first two decades of Lavender conferences reflected changing trends in the field, a theme I continue here. His corpus analysis of abstracts for papers presented between 1994-2012 revealed a decline in the explicit labelling of 'gay(s)' and 'lesbians', while 'queer' and 'LGBT' were rising. This indicates, he suggests, a move beyond looking at dominant categories as homogenous identities towards a more inclusive understanding of non-normative sexuality. Indeed, whereas earlier research into language and sexuality was often described as 'gay and lesbian linguistics', driven by the desire to 'put lesbian and gay male speakers on the sociolinguistic map' (Motschenbacher 2011: 15), much recent work has been more concerned with exploring the mechanisms by which all sexual identities are realised and communicated through language.

This is not to say that studies focused on gay men and lesbians have ceased, however. The past decade has seen monographs exploring identity construction amongst these groups specifically, including Barrett's (2017) expansive account of language use in gay male subcultures across the USA and Jones's (2012) focused ethnography of a lesbian community of practice in the UK. Other studies in UK contexts have also explored lesbian subjectivities as they are realised in interactions between groups of mixed-sexuality women (e.g. Sauntson \& Morrish 2012) as well as the representation of lesbian identities in media spaces created by and for queer women (e.g. Bailey 2019, Turner 2015). Studies into stereotypes of gay male speech have included those in Italy (Russell 2015), Spain (Hadodo \& Kanwit 2020), Thailand 
(Osatananda \& Gadavanij 2019) and North America (Mann 2012, Zimman 2013), and research has considered the co-construction of meaning on gay male dating sites (AdamsThies 2019, Baudinette 2017). Rather than framing gay or lesbian identities as homogenous or essentialised categories, though, these studies tend to treat the communities under examination as case studies; they enable the theorisation of how norms surrounding gender and sexuality are negotiated, challenged, and articulated in queer contexts.

What we have not seen in the past ten years, which we might have expected given the data in Baker (2013), is a marked increase in research specifically focused on more diverse sexual identity categories. When specific categories are foregrounded or focused upon, they are still more often than not gay and lesbian - perhaps reflecting the ongoing dominance of these identities in queer culture. The sexual identity category 'bisexual' remains underexplored (though see Thorne 2013 and Wright 2017), as does pansexuality (though see Cordoba 2020 on non-binary sexualities more generally), and research has only recently been published on asexuality (Fine 2019).

There has, however, been a notable increase in research over the past decade which goes beyond sexuality to consider trans and/or non-binary identities. Zimman has led the field in exploring the sociophonetic realisation of transmasculine identities (Zimman 2013) as well as the discursive relationship between trans identity and embodiment (Zimman 2014). Building on this, studies have used discourse analysis to examine the construction of transspecific identities in online contexts (Dame 2013, Jones 2019, Webster 2018), in clinical settings (Borba 2019, Borba \& Milani 2017), and through sociolinguistic interviews (Cashman 2018). Furthermore, Corwin's (2017) analysis of embodied identity construction shows how genderqueer individuals reposition gender as non-binary through their gestures and language. Trends at Lavender suggest we will see more research focused on non-binary identities emerging over the next few years; $20 \%$ of the abstracts accepted for presentation at 
the 2020 conference in San Francisco (postponed until 2021 due to Covid-19) were focused specifically on identities falling under the umbrella of 'trans'. It is similarly notable that, although the name of this journal suggests an emphasis on sexuality alone, in practice what is published within it is more broadly focused on all queer identities.

Baker (2013: 188) also notes increasing use of the term 'queer' at Lavender, suggesting it signifies 'a gradual acceptance of and/or interest in queer theory in general by people attending the conference'. Queer theory's focus on challenging normative ideas of gender and sexuality enables the interrogation of discourse which keeps LGBT people in their place, so it is no surprise that it has been central to work in the field for many years. As Motschenbacher (forthcoming) points out, queer theory has been associated with research into language, gender and sexuality since Queerly Phrased was published (Livia \& Hall 1995), but it is only relatively recently that the concept of 'queer linguistics' has become salient. Motschenbacher and Stegu (2013: 521) describe the aim of queer linguistics as providing 'analyses of language data that are informed by the insights of Queer Theory', arguing that it has become the dominant approach in the field since the early 2000s. This argument seems to be supported by Baker's (2013: 201) analysis of Lavender abstracts, as he finds that 'there has also been a move away from the idea of LGBT people as having their own language (or culture) and greater focus on critiquing (hetero)normative discourses'. As discussed in the following section, a focus on deconstructing normativities has become central to much work in language and sexuality.

\section{Challenging normativity}

Baker (2013) identifies an increase in abstracts focused on homophobia during the later years of the conference, and this trend has certainly continued in the field. As queer theory has 
become an established approach for the study of language and sexuality, so heteronormativity has been more explicitly critiqued. Heteronormativity is 'a subtle cultural system which serves to maintain a gender and sexual order which is driven by "opposite-sex" attraction; through this system, homophobic discourses are enabled' (van der Bom, Coffey-Glover, Jones, Mills \& Paterson 2015: 110). Importantly, as shown by Sauntson (2018), heteronormativity does not necessarily always lead to homophobic discourse; her analysis of policy and practice in UK and US education suggests that the assumptions made about relationships and the silence around sexual diversity may be the bigger challenge. Nonetheless, research in language and sexuality has continued to foreground the linguistic mechanisms by which homophobic discourse does emerge, particularly within institutional contexts. These include Chojnicka's (2015) account of how NGOs in three Eastern European countries position sexual minorities as a threat, and Peterson's (2016) identification of homophobic strategies in America's 'Don't Ask Don't Tell' policy.

As same-sex marriage has been legalised in a number of countries around the world over the past decade, research has charted the language used to talk about it. A number of these have emerged from the British context, finding that homophobic sentiments in relation to the legislation tend to be expressed implicitly (van der Bom et al. 2015, Findlay 2017, Love \& Baker 2015, Turner, Mills, van der Bom, Coffey-Glover, Paterson \& Jones 2018; Paterson \& Coffey-Glover 2018). These studies demonstrate that whilst, in many Western contexts, there have recently been great strides towards equality for LGBT people, this does not mean homophobia has been eradicated - as Leap's (2010) analysis of American gay men's narratives shows, it remains a very real threat. What we do see now, though, is a more implicit expression of homophobia due to the stigma it now carries. This has been shown again very recently in analyses of discourse associated with the HIV prevention drug PrEP; studies have demonstrated how newspaper reports subtly reproduce stereotypes of gay men as 
promiscuous risk-takers in relation to the medication (Jones \& Collins 2020, Mowlabocus 2020).

While homophobia has in many contexts become less explicit, the same cannot be said of transphobia. Jones (2020) shows young trans people in England describing their experiences of othering, while Derecka (2019) argues that the anonymity of online spaces facilitates the marginalisation of trans people in Poland. It is also clear that the British tabloid press in particular continues to have a central role in the reproduction of discourse which frames trans subjects as dangerous or deviant (Baker 2014, Gupta 2018, Zottola 2018). We should hope that we will see analyses showing a decline in transphobic discourse in the media and institutional texts over the coming years - but either way, this is an area deserving much more critical attention.

A concept of increasing importance in queer theory since its introduction by Duggan (2002) is homonormativity: the assimilationist 'mainstreaming' of gay culture in line with heteronormative ideals. Duggan sees this trend as emerging from the shifting focus of queer politics - and indeed the depoliticised nature of LGBT culture - towards domestic equality, which she frames as restrictive and damaging. This notion of assimilation has received critique from queer linguists recently, who argue that homonormative identities are not necessarily depoliticised. Bailey's (2019) analysis of a queer women's website, for example, reveals clear political intent in the representation of both bisexual and trans women in its pages; despite this, a heteronormative, gender-conforming version of lesbian identity ultimately dominates. Furthermore, Hall (2013) problematises the very idea that homonormativity concerns the appropriation of heteronormativity, given that the social meaning of heteronormativity itself is not stable. She argues that our idea of what is truly 'queer' will shift over time; this is especially true as LGBT people gain equal rights, and concepts such as marriage change to be more inclusive. 
However, queer linguistic work has provided evidence of other aspects of homonormativity. Gay people who adhere to broadly heteronormative styles and behaviours - i.e. those who do not seem 'very gay' - are often identified as homonormative, and queer linguistic research has shown how this type of gay identity is privileged in discourse. Milani and Levon (2016), for example, engage with the concept of 'pink-washing' at Tel Aviv Pride in Israel; they show how the representation of queer culture is dominated by images of normatively masculine, rugged gay men who reflect Israeli ideals of gender.

Motschenbacher's (2020) multimodal analysis of a Floridian LGBT linguistic landscape also reveals the consumption-driven representation of a mostly gender-normative, white, affluent ideal - one which is also reflected in Adams-Thies' (2019) analysis of American gay men's hook-up sites. Comer's (2018) multimodal account of LGBTQ tourism in South Africa similarly reveals the valorisation of capitalist-driven gay identities which are typically male, muscular, cosmopolitan, and white.

The potentially negative impact of this restrictive notion of 'ideal' gay identity on queer communities is demonstrated through my own recent work with an LGBT youth group (Jones 2018). The young people articulate a desire to conform to normative ideals which mean they will not stand out as 'other'; they resist LGBT-specific activities such as Pride events and avoid behaviours or styles that would mark them out as queer. Yet while they aspire to be homonormative, as working-class youth in a rural location they have little opportunity to engage in the kind of gay culture described above: that which targets the affluent and urban. Furthermore, it is clear from their interaction together that this desire to be normative is rooted not in their sense of entitlement to equality, but the relentless homophobia they experience in their small town. Simply put, the young people align themselves with heteronormativity in order to avoid being demonised as queer. To 
understand LGBT identities, it is therefore clear that we must think intersectionally, since a person's experience of being queer is always dictated by other sociocultural factors.

Thinking intersectionality means acknowledging that various aspects of a person's experience combine to marginalise them in different ways, depending for example on their race, class, or sexuality (Crenshaw 1991). Work in queer linguistics has begun to explore this over the past decade. Provencher (2017), for instance, shows how French Arabic men negotiate multiple competing discourses in the realisation of their queer identities. Cashman (2018) provides narrative analysis of the speech of a trans woman who is a Mexican immigrant in the USA, showing how her talk brings out the "complexity of the various identifications that intersect in her experiences' (Cashman 2018: 432), making relevant her ethnicity, gender, age, and a host of other identities. Shrikant (2014) shows how the concept of being a 'gold star' lesbian (having never slept with a man) may be a prevalent part of lesbian discourse only for those who were raised in liberal families and communities - one of Shrikant's African-American participants frames this as indicative of the whiteness of queer culture. Reflecting this, Lopez and Bucholtz (2017) point out that much research into queer identities within sociolinguistics still remains dominated by whiteness, with Black culture in particular being poorly represented. In their analysis of 'authentically queer' Black characters on the television drama The Wire, they show how Blackness remains bound tightly to heteronormative masculinity; this demonstrates the importance of looking critically at the relationship between race and queerness.

Another key intersection being explored within language and sexuality is that between religion and queerness. Levon's (2016) sociophonetic analysis of creaky voice use by an Orthodox Jewish man who experiences same-sex desire demonstrates the role of linguistics in exploring intersectionality, as the speaker positions himself as both queer and as committed to his religion (which does not allow homosexuality). Similarly, Thompson's (2019) 
discourse analysis of narratives produced by LGBT Muslims in the US shows participants simultaneously indexing queerness and Muslimness by effectively creating a space for themselves which legitimises the intersection of these two seemingly clashing identities. Afzal's (2014) ethnographic analysis with Muslim American gay men of Pakistani descent further shows how the construction of complex identities with competing intersecting parts is linguistically possible. In analysing the realisation of identities in relation to multiple forms of marginalisation, these studies certainly reflect the aims of queer linguistics more broadly. As the field continues to expand its horizons, so we can hope to see much more explicit focus on the intersection of gender and sexuality with race, religion, socioeconomic class, nationality, and with embodied forms of marginalisation such as disability.

\section{Conclusion}

The past ten years have further cemented the prevalence of queer theory in the field of language and sexuality, with a continued rise in studies challenging and critiquing dominant cultural norms associated with gender and sexuality. In recent years, we have also seen a growth in scholarship focused on marginalisation along axes of oppression which intersect with sexuality. Far more research now takes place that considers a range of gender identities, and work is emerging which focuses on non-binary sexualities, too; Lavender, like this journal, has had a defining role to play in creating an environment where this work can flourish. Research remains dominated by Western scholarship, an observation originally noted in the inaugural issue of this journal (Leap \& Motschenbacher 2012), but the global outlook of $J L S$ (along with the international reach of Lavender) will continue to be key to increasing diversity in the field. For this to continue, we will ideally see the conference being hosted outside of Europe and North America in the near future, as well as more $J L S$ special 
issues focused on queerness in relation to globalisation, migration, transnational identity, and non-Anglophone populations. There is much to look forward to!

\section{References}

Adams-Thies, B. 2019. Hooking up mildly or wildly: Linguistic interventions for the negotiation of gay male desires. Journal of Language and Sexuality 8(1): 108-131.

Afzal, Ahmed. 2014. 'Being gay has been a curse for me': Gay Muslim Americans, narrative and negotiations of belonging in the Muslim ummah. Journal of Language and Sexuality 3(1): 60-86.

Bailey, Aimee. 2019. 'Girl-on-girl culture': Constructing normative identities in a corpus of sex advice for queer women. Journal of Language and Sexuality 8(2): 195-220.

Baker, Paul. 2013. From gay language to normative discourse: A diachronic corpus analysis of Lavender Linguistics conference abstracts 1994-2012. Journal of Language and Sexuality 2(2): 179-205.

Baker, Paul. 2014. 'Bad wigs and screaming mimis': Using corpus-assisted techniques to carry out critical discourse analysis of the representation of trans people in the British press. In Contemporary Critical Discourse Studies, Christopher Hart \& Piotr Cap (eds), 211-236. London: Bloomsbury.

Barrett, Rusty. 2017. From Drag Queens to Leathermen: Language, Gender, and Gay Male Subcultures. Oxford: Oxford University Press.

Baudinette, Thomas. 2017. Constructing identities on a Japanese gay dating site: Hunkiness, cuteness and the desire for heteronormative masculinity. Journal of Language and Sexuality 6(2): 232-261. 
Borba, Rodrigo. 2019. The interactional making of a 'true transsexual': Language and (dis)identification in trans-specific healthcare. International Journal of the Sociology of Language 256: 21-55.

Borba, Rodrigo \& Milani, Thommaso. 2017. The banality of evil: Crystallised structures of cisnormativity and tactics of resistance in a Brazilian gender clinic. Journal of Language and Discrimination 1(1): 7-33.

Cashman, Holly R. 2018. Narrating the intersection: time, space, and transition in one queer life. Gender and Language 12(4): 416-436.

Chojnicka, Joanna. 2015. Homophobic speech in post-socialist media: A preliminary typology of homophobic manipulative discourse. Journal of Language and Sexuality 4(1): $138-173$.

Comer, Joseph. 2018. 'Equality on the sea': Interrogating LGBTQ privilege in the tourism discourse of Africa's 'gay capital'. Gender and Language 12(4): 479-503.

Cordoba, Sebastian. 2020. Exploring Non-Binary Genders: Language and Identity. Unpublished PhD thesis: De Montfort University.

Corwin, Anna I. 2017. Emerging genders: Semiotic agency and the performance of gender among genderqueer individuals. Gender and Language 11(2): 255-277.

Crenshaw, Kimberle. 1991. Mapping the margins: Intersectionality, identity politics, and violence against women of color. Stanford Law Review 43(6): 1241-1299.

Dame, Avery. 2013. 'I'm your hero? Like me?' The role of 'expert' in the trans male vlog. Journal of Language and Sexuality 2(1): 40-69. 
Derecka, Magdalena. 2019. Manifestations of transphobia in computer mediated communication. A case study of language discrimination in English and Polish internet-mediated discourse. Studies in Polish Linguistics 14(3): 101-123.

Duggan, Lisa. 2002. The new homonormativity: The sexual politics of neoliberalism. In Materializing Democracy, Russ Castronovo \& Dana D. Nelson (eds), 175-193. Durham: Duke University Press.

Findlay, Jamie Y. 2017. Unnatural acts lead to unconsummated marriages: Discourses of homosexuality within the House of Lords debate on same-sex marriage. Journal of Language and Sexuality 6(1): 30-60.

Fine, Julia Coombs. 2019. Performing graysexuality: A segmental and prosodic analysis of three voices employed in the construction of the graysexual self. Journal of Language and Sexuality 8(1): 1-29.

Gupta, Kat. 2018. Response and responsibility: Mainstream media and Lucy Meadows in a post-Leveson context. Sexualities 22(1-2): 31-47.

Hadodo, Matthew John \& Kanwit, Matthew. 2020. Menos masculino, demasiado infantil: How age and gender ideologies index sexuality in diminutive perception in Madrid Spanish. Journal of Language \& Sexuality 9(2): 127-150.

Hall, Kira. 2013. 'It's a hijra!': Queer linguistics revisited. Discourse \& Society 24(5): 634642.

Jones, Lucy. 2012. Dyke/Girl: Language and Identities in a Lesbian Group. Basingstoke: Palgrave Macmillan.

Jones, Lucy. 2018. 'I'm not proud, I'm just gay': Lesbian and gay youths' discursive negotiation of otherness. Journal of Sociolinguistics 22(1): 55-76. 
Jones, Lucy. 2019. Discourses of transnormativity in vloggers' identity construction. International Journal of the Sociology of Language 256: 85-101.

Jones, Lucy. 2020. Subverting transphobia and challenging ignorance: The interactive construction of resistant identity in a community of practice of transgender youth. Journal of Language and Discrimination 4(2): 202-225.

Jones, Lucy \& Collins, Luke. 2020. PrEP in the press: A corpus-assisted discourse analysis of how users of HIV-prevention treatment are represented in British newspapers. Journal of Language \& Sexuality 9(2): 201-224.

Leap, William (ed). 1995. Beyond the Lavender Lexicon: Authenticity, Imagination, and Appropriation in Lesbian and Gay Languages. Amsterdam: Gordon and Breach.

Leap, William. 2010. Homophobia as moral geography. Gender and Language 4(2): 187220.

Leap, William \& Motschenbacher, Heiko. 2012. Launching a new phase in language and sexuality studies. Journal of Language and Sexuality 1(1): 1-14.

Levon, Erez. 2016. Conflicted selves: language, sexuality and religion in Israel. In Language, Sexuality and Power: Studies in Intersectional Sociolinguistics, Erez Levon \& Ronald Beline Mendes (eds), 215-239. Oxford: Oxford University Press.

Livia, Anna \& Hall, Kira (eds). 1997. Queerly Phrased: Language, Gender and Sexuality. London: Routledge.

Lopez, Qiuana \& Bucholtz, Mary. 2017. 'How my hair look?': Linguistic authenticity and racialized gender and sexuality on The Wire. Journal of Language and Sexuality 6(1): $1-29$. 
Love, Robbie \& Baker, Paul. 2015. The hate that dare not speak its name? Journal of Language Aggression and Conflict 3(1): 57-86.

Mann, Stephen L. 2012. Speaker attitude as a predictive factor in listener perception of gay men's speech. Journal of Language and Sexuality 1(2): 206-230.

Milani, Tommaso \& Levon, Erez. 2016. Sexing diversity: Linguistic landscapes of homonationalism. Language and Communication 51: 69-86.

Motschenbacher, Heiko. 2011. Taking queer linguistics further: Sociolinguistics and critical heteronormativity research. International Journal of the Sociology of Language 212: $149-179$.

Motschenbacher, Heiko. 2020. Walking on Wilton Drive: A linguistic landscape analysis of a homonormative space. Language \& Communication 72(2): 25-43.

Motschenbacher, Heiko. forthcoming. Language and sexuality normativity. In Oxford Handbook of Language and Sexuality, Rusty Barrett and Kira Hall (eds). Oxford: Oxford University Press.

Motschenbacher, Heiko \& Stegu, Martin. 2013. Introduction: Queer linguistic approaches to discourse. Discourse \& Society 24(5): 519-535.

Mowlabocus, Sharif. 2020. 'What a skewed sense of values': Discussing PreP in the British press. Sexualities 23(8): 1343-1361.

Osatananda, Varisa \& Gadavanij, Savitri. 2019. Materializing gay identity: An analysis of gay-sounding speech in Thai. Journal of Language and Sexuality 8(1): 30-52.

Paterson, Laura L. \& Coffey-Glover, Laura. 2018. Discourses of marriage in same-sex marriage debates in the UK press 2011-2014. Journal of Language and Sexuality 7(2): 175-204. 
Peterson, David. 2016. Homophobic grammar: The role of transitivity and phoricity in homophobic formation. Journal of Language and Sexuality 5(1): 61-93.

Provencher, Denis M. 2017. Queer Maghrebi French: Language, Temporalities, Transfiliations. Liverpool: Liverpool University Press.

Russell, Eric. 2015. Sounding gay and sounding straight: The performance of male sexual identity in Italian. Journal of Language and Sexuality 4(1): 30-76.

Sauntson, Helen. 2018. Language, Sexuality and Education. Cambridge: Cambridge University Press.

Sauntson, Helen \& Morrish, Elizabeth. 2012. How gay is football this year? Identity and intersubjectivity in a women's sports team. Journal of Language and Sexuality 1(2): $151-178$.

Shrikant, Natasha. 2014. 'It's like, 'I've never met a lesbian before!': Personal narratives and the construction of diverse female identities in a lesbian counterpublic. Pragmatics 24(4): 799-818.

Thompson, Katrina Daly. 2019. Becoming Muslims with a 'queer voice': Indexical disjuncture in the talk of LGBT members of the progressive Muslim community. Journal of Linguistic Anthropology 30(1): 123-144

Thorne, Lisa. 2013. 'But I'm attracted to women': Sexuality and sexual identity performance in interactional discourse among bisexual students. Journal of Language and Sexuality 2(1): 70-100.

Turner, Georgina. 2015. A real lesbian wouldn't touch a bisexual with a bargepole. Critical Discourse Studies 12(2): 139-162. 
Turner, Georgina, Mills, Sara, van der Bom, Isabelle, Coffey-Glover, Laura, Paterson, Laura L. \& Jones, Lucy. 2018. Opposition as victimhood in newspaper debates about samesex marriage. Discourse \& Society 29(2): 180-197.

van der Bom, Isabelle, Coffey-Glover, Laura, Jones, Lucy, Mills, Sara \& Paterson, Laura. 2015. Implicit homophobic argument structure: Equal-marriage discourse in The Moral Maze. Journal of Language and Sexuality 4(1): 102-137.

Webster, Lexi. 2018. 'I wanna be a toy': Self-sexualisation in gender-variant twitter users' biographies. Journal of Language and Sexuality 7(2): 205-236.

Wright, Lyn. 2017. Bilingual/bisexual: Linguistic and sexual fluidity in fictional accounts of bilingualism and language learning. Journal of Language and Sexuality 6(1): 177203.

Zimman, Lal. 2013. Hegemonic masculinity and the variability of gay-sounding speech: The perceived sexuality of transgender men. Journal of Language \& Sexuality 2(1): 1-39.

Zimman, Lal. 2014. The discursive construction of sex: Remaking and reclaiming the gendered body in talk about genitals among trans men. In Queer Excursions: Rethinking Binaries in Language, Gender, and Sexuality, Lal Zimman, Jenny L. Davis \& Joshua Raclaw (eds), 13-34. Oxford: Oxford University Press.

Zottola, Angela. 2018. Transgender identity labels in the British press: A corpus-based discourse analysis. Journal of Language and Sexuality 7(2): 237-262.

\section{Address for correspondence}

Lucy Jones

School of English 
University of Nottingham

Nottingham NG7 2RD

United Kingdom

lucy.jones@nottingham.ac.uk 